\title{
ANALISIS PENDAPATAN USAHA GULA KELAPA DI DESA SIALANG JAYA KECAMATAN BATANG TUAKA KABUPATEN INDRAGIRI HILIR
}

\author{
Ridwan Nulkarim \\ Program Studi Agribisnis Fakultas Pertanian UNISI \\ Email: ridwanulkarim27@gmail.com
}

\begin{abstract}
ABSTRAK
Usaha Gula Kelapa adalah salah satu usaha yang berkembang cukup baik di Desa Sialang Jaya Kecamatan Batang Tuaka.Oleh karena itu, perlu dilakukan analisis keuntungan dan efesiensi usaha gula kelapa yang ada di Desa Sialang Jaya. Tujuan penelitian adalah: untuk mengetahui besarnya keuntungan yang diperoleh dari usaha gula kelapa kelapa dan untuk mengetahui tingkat efisiensi usaha gula kelapa..Metode analisis data yang digunakan dalam penelitian ini adalah dengan menggunakan alat analisis biaya, penerimaan, keuntungan, pendapatan kerja keluarga dan efisiensi usaha.Pengambilan sampel dilakukan melalui observasi dan wawancara langsung menggunakan kuisioner. Hasil penelitian menunjukkan bahwa : total biaya pada usaha gula kelapa kelapa yaitu biaya tidak tetap sebesar Rp.66.572,53 dan biaya tetap sebesar Rp.779,44. Rata - rata penerimaan yang diperoleh sebesar Rp. 202.800,00 per produksi. Ratarata keuntungan yang diperoleh adalah sebesar Rp.135.448,03 per produksi. Rata - rata pendapatan kerja keluarga sebesar Rp. 166.227,47 per produksi. Nilai RCR adalah sebesar 2.94 yang berarti usaha gula kelapa efesien.
\end{abstract}

Kata Kunci : Gula Kelapa, Keuntungan, Efisiensi

\begin{abstract}
Coconut Sugar Business is one of the businesses that has developed quite well in Sialang Jaya Village, Batang Tuaka District. Therefore, it is necessary to analyze the profitability and efficiency of the coconut sugar business in Sialang Jaya Village. The research aims to analyze the profits of the coconut palm sugar business and to analyze the efficiency of the coconut sugar business. Data were analyzed using analysis of costs, revenues, profits, family work income and business efficiency. Sampling was done through observation and direct interviews using questionnaires. The results showed that: the total cost of the coconut sugar business is a variable cost of Rp.66,572.53 and a fixed cost of Rp.779.44. The average revenue is Rp. 202,800.00 per production. The average profit is Rp.135,448.03 per production. The average family work income is Rp. 166,227.47 per production. RCR value is 2.94 , which means efficient coconut sugar business.
\end{abstract}

Keywords: Coconut Sugar, Benefits, Efficiency 


\section{PENDAhuluan}

Salah satu produk turunan kelapa yang banyak diusahakan oleh masyarakat khususnya di pedesaan adalah gula kelapa. Gula kelapa adalah bahan pemanis yang merupakan hasil olahan nira kelapa. Nira adalah cairan manis yang diperoleh dengan melakukan penyadapan terhadap bunga kelapa (mayang) yang belum membuka pada stadia umur tertentu.

$$
\text { Kecamatan Batang Tuaka }
$$

merupakan salah satu Kecamatan di Kabupaten Indragiri Hilir, dimana di Kecamatan tersebut memiliki jumlah pengusaha gula kelapa yang cukup banyak. Salah satu desa yang memiliki banyak pengusaha gula kelapa adalah Desa Sialang Jaya. Industri gula kelapa yang berada di Desa Sialang Jaya merupakan industri berskala rumah tangga, dimana penggunaan tenaga kerjanya yaitu tenaga kerja dalam keluarga. Industri gula kelapa di Desa Sialang Jaya telah ada berlangsung secara turun temurun dan masih bersifat tradisional, baik dalam proses produksi maupun pemasarannya. Namun pendapatan dari industri gula kelapa ini mampu memberikan kontribusi yang cukup besar terhadap pendapatan rumahtangga.

Produsen gula kelapa yang ada di Desa Sialang Jaya selama ini belum memperhatikan manajemen usaha, terutama yang berkaitan dengan besarnya biaya, penerimaan, keuntungan dan efisiensi usaha, sehingga perlu dilakukan kajian mengenai analisis tersebut untuk melihat keuntungan usaha dan untuk mengetahui apakah usaha tersebut layak untuk di lakukan agar usaha gula kelapa yang ada di Desa Sialang Jaya Kecamatan Batang Tuaka dapat terus dikembangkan.

Berdasarkan latar belakang tersebut maka tujuan dari penelitian ini adalah untu mengetahui seberapa besar keuntungan yang diterimaoleh produsen gula kelapa di Desa Sialang Jaya dan untuk mengetahui tingkat efisiensi dari usaha pembuatan gula kelapa di Desa Sialang Jaya.

\section{METODOLOGI PENELITIAN \\ 2.1 Waktu dan Tempat Penelitian}

Penelitian ini dilakukan di Desa Sialang Jaya Kecamatan Batang Tuaka Kabupaten Indragiri Hilir. Penentuan lokasi penelitian ini dipilih secara purposive (sengaja) dengan beberapa pertimbangan bahwa wilayah tersebut memiliki banyak produsen gula kelapa yang melakukan usahanya. Penelitian ini dilakukan selama kurang lebih 3 bulan yaitu pada bulan November sampai dengan bulan Januari 2018 .

\subsection{MetodePengambilanSampel}

Populasi dalam penelitian ini adalah pengrajin gula kelapa yang berproduksi di Desa Sialang Jaya Kecamatan Batang Tuaka yaitu sebanyak 112 Orang, dari jumlah populasi tersebut dapat diambil sampel sebanyak $30 \%$ sehingga di peroleh sampel sebanyak 25 Orang pengrajin gula kelapa. Metode yang digukan untuk menentukan jumlah sampel yaitu dengan menggunakan metode (Random Sampling) yaitu dengan pengambilan sampel secara acak.

\subsection{MetodeAnalisis Data}

\subsubsection{BiayaProduksi}

Melakukan kegiatan usaha agroindustri gula kelapa ada biaya yang dikeluarkan yaitu biaya tetap (FC) dan biaya variabel (VC). Untuk mengetahui total biaya produksi secara matematis dirumuskan sebagai berikut :

$$
\mathrm{TC}=\mathrm{FC}+\mathrm{VC}
$$

Keterangan : $\mathrm{TC}=$ Total Cost atau biaya total (Rp/produksi) 


$$
\begin{aligned}
& \mathrm{FC}=\text { Fix Cost } \text { atau biaya } \\
& \text { tetap(Rp/produksi) } \\
& \mathrm{VC}=\text { Variabel Costbiaya } \\
& \text { tidak tetap(Rp/produksi) }
\end{aligned}
$$

\subsubsection{PenyusutanAlat}

Untuk menghitung biaya penyusutan alat dalam usaha tersebut dihitung dengan metode garis lurus dengan rumus sbb:

$$
\mathrm{D}=\frac{\mathrm{C}-\mathrm{SV}}{\mathrm{UL}}
$$

Keterangan :

$\mathrm{D}=$ Nilai penyusutan alat $(20 \% \mathrm{x}$ Nilaibeli)

$\mathrm{C}=$ Harga beli alat

$\mathrm{SV}=$ Nilai sisa alat

$\mathrm{UL}=$ Masa pakai alat

\subsubsection{Penerimaan}

Penerimaan (Pendapatan kotor) dari usahaagroindustri gula kelapa adalah perkalian antara jumlah produksi yang diperoleh dengan harga yang berlaku dipasar (Soekartawi, 1998). Secara matematis rumusnya adalah sebagai berikut:

$$
\mathrm{TR}=\mathrm{Q} \times \mathrm{P}
$$

Keterangan : $\mathrm{TR}=$ Total Revenue atau penerimaantotal(Rp/produksi)

$$
\begin{aligned}
& \mathrm{Q}=\text { Quantity atau banyaknya } \\
& \text { jumlah } \\
& \text { produksi }(\mathrm{Kg} / \text { produksi }) \\
& \mathrm{P}=\text { Price } \text { atau harga yang }
\end{aligned}
$$

berlaku dipasar( $\mathrm{Rp} / \mathrm{kg})$

Dengan rumus diatas maka hasil dari gulakelapa yang didapat merupakan fungsi dari jumlah produksi gula juruh yang terjual dengan harga yang berlaku dipasar.

\subsubsection{Keuntungan}

Keuntungan (Pendapatan bersih) adalah selisih antara penerimaan dan semua biaya selama periode tertentu. Dapat ditulis dengan rumus sebagai berikut:

$$
\pi=\mathrm{TR}-\mathrm{TC}
$$

Keterangan: $\pi=$ Incomeatau PendapatanBersih (Rp/produksi)
$\mathrm{TR}=$ Total Revenue atau penerimaantotal(Rp/produksi)

$\mathrm{TC}=$ Total Cost atau biaya total yang dikeluarkan selama proses produksi

(Rp/produksi).

\subsubsection{Pendapatan Kerja Keluarga}

Menurut Hernanto (1989), untuk menghitung pendapatan keluarga digunakan rumus sebagai berikut :

Keterangan :

$$
\mathrm{PKK}=\pi+\mathrm{TKDK}+\mathrm{D}
$$

PKK = Pendapatan kerja keluarga

(Rp/bulan)

$$
\begin{array}{ll}
\pi & =\text { Keuntungan (Rp/Bulan) } \\
\text { TKDK } & =\text { Upah tenaga kerja dalam keluarga } \\
\mathrm{D} & =\text { Penyusutan Alat }
\end{array}
$$

\subsubsection{Efisiensi}

Menurut Soekartawi (2002), analisis Return Cost (R/C) ratio merupakan perbandingan (ratio atau nisbah) antara penerimaan (revenue) dan biaya (cost). Yang dikeluarkan dalam satu kali produksi. Untuk mengetahui efisiensi, maka rumus yang dipakai yaitu:

$$
\text { Efisiensi }=\mathrm{R} / \mathrm{C}
$$

Keterangan : $\mathrm{R}=$ Penerimaan total usaha produksi gula kelapa ( $\mathrm{Rp} /$ produksi)

$$
\mathrm{C}=\text { Total biaya yang }
$$

dikeluarkan (Rp/produksi)

Kriteria yang digunakan dalam penilaian efisiensi usaha adalah :

$\mathrm{R} / \mathrm{C}$ Ratio > 1, Usaha pengolahan gula kelapa dinyatakanlayak.

$\mathrm{R} / \mathrm{C}$ Ratio = 1, Usaha pengolahan gula kelapa dinyatakan berada pada titik impas.

$\mathrm{R} / \mathrm{C}$ Ratio < 1, Usaha pengolahan gula kelapa tidak layak.

\section{III.HASIL DAN PEMBAHASAN \\ 3.1. Biaya Produksi}

Biaya produksi merupakan biaya yang dikeluarkan oleh pengusaha gula 
kelapa selama melakukan kegiatan usahanya dimulai dari proses produksi hingga menghasilkan produk, yang meliputi biaya tetap dan biaya tidak tetap. Biaya tetap adalah biaya yang relatif tetap jumlahnya, dan terus dikeluarkan walaupun produksi yang diperoleh banyak atau sedikit sedangkan biaya tidak tetap adalah biaya yang besar kecilnya dipengaruhi oleh produksi yang diperoleh. Rincian biaya produksi yang dikeluarkan dalam usaha pengolahan gula kelapa di Desa Sialang Jaya dapat dilihat pada Tabel 1.

Tabel 1. Analisis Biaya Produksi Usaha Pengolahan Gula Kelapa Per Produksi

\begin{tabular}{|c|c|c|c|}
\hline Biaya & Satuan & $\begin{array}{l}\text { Harga } \\
(\mathbf{R p})\end{array}$ & Jumlah (Rp) \\
\hline \multicolumn{3}{|l|}{ Biaya Tidak Tetap } & $25.480,00$ \\
\hline \multicolumn{4}{|l|}{ b. BahanPengemasan } \\
\hline i.Plastik & $\mathrm{Kg}$ & 1.000 & 650,00 \\
\hline ii.Tali & Ikat & 1.000 & 173,20 \\
\hline iii.Asoy Besar & Buah & 1.000 & 840,00 \\
\hline \multicolumn{4}{|l|}{ c.Bahan Penunjang } \\
\hline i. Resak & $\mathrm{Kg}$ & 17.500 & 9333,33 \\
\hline ii. Pengawet & $\mathrm{Gr}$ & 6.000 & $2.136,00$ \\
\hline d. Bahan Bakar & $\mathrm{Rp}$ & & $2.626,67$ \\
\hline e. Biaya Transportasi & $\mathrm{Rp}$ & & $3.733,33$ \\
\hline f. Biaya Tenaga Kerja & $\mathrm{Rp}$ & & $30.000,00$ \\
\hline Jumlah & & & $66.572,53$ \\
\hline Biaya Tetap & $\mathrm{Rp}$ & & \\
\hline Penyusutan Alat & $\mathrm{Rp}$ & & 779,44 \\
\hline Total & & & $67.351,97$ \\
\hline
\end{tabular}

Sumber : Data primer diolah, 2018

Pada usaha pengolahan gula kelapa di Desa Sialang Jaya biaya tidak tetap terdiri dari bahan baku yaitu nira kelapa, biaya pengemasan yaitu plastik, karet, , dan asoy besar, kemudian bahan bakar, yang terakhir yaitu biaya tenaga kerja dalam keluarga. Sedangkan biaya tetap terdiri dari biaya penyusutan alat yang terdiri dari parang, sabit, kuali, sendok pengaduk, cetakan bambu , saringan, toples, ember dan timbangan.

\subsubsection{Biaya Tidak Tetap}

Biaya tidak tetap adalah biaya yang sifatnya berubah - ubah tergantung dari besar kecilnya produksi yang dihasilkan
(Soekartawi, 1998). Biaya variabel dalam dalam usaha pengolahan gula kelapa terdiri dari biaya bahan baku, biaya pengemasan, dan biaya tambahan yeng terdiri dari bahan bakar dan biaya transportasi. Pada Tabel 1 menunjukkan bahwa biaya tidak tetap dari usaha pengolahan gula kelapa di Desa Sialang Jaya terdiri dari biaya bahan baku sebesar Rp. 25.480,00 bahan baku yaitu nira kelapa. Biaya pengemasan yang terdiri dari plastik sebesar Rp. 650,00, tali sebesar Rp. 173,20 , dan asoy besar yaitu sebesar Rp. 840,00 , biaya bahan bakar sebesar Rp. 2.626,67, biaya trasnportasi sebesar Rp. 3.733,33 dan yang terakhir adalah biaya tenaga kerja sebesar Rp. 30.000,00. Maka 
dari itu dapat diketahui biaya tidak tetap sebesar Rp. 66.572,53 per perhari.

\subsubsection{Biaya Tetap}

Biaya tetap adalah biaya yang relatif jumlahnya dan harus dikeluarkan walaupun produk yang dihasilkan banyak atau sedikit (Soekartawi, 1998). Pada Tabel 1 menunjukan bahwa biaya tetap terdiri dari biaya penyusutan alat per produksi sebesar Rp779,44. Biaya penyusutan ini dihitung dari masing - masing peralatan yang ditentukan oleh banyaknya masing - masing alat yang digunakan dan umur ekonomisnya. Biaya penyusutan yang dimaksud disini adalah penyusutan alat-alat yang digunakan dalam pengolahan gula kelapa, terdiri dari parang, sabit, kuali, sendok pengaduk, cetakan bambu, toples, ember dan timbanganBiaya penyusutan yang dihitung pada usaha ini dihitung dalam periode per produksi.

\subsubsection{Total Biaya}

Menurut Soekartawi (1998), total biaya adalah keseluruhan biaya tetap ditambah dengan biaya tidak tetap. Biaya total merupakan biaya yang dikeluarkan oleh pengusaha gula kelapa secara keseluruhan.
Dari tabel 6 memperlihatkan bahwa total biaya usaha pengolahan gula kelapa di daerah penelitian adalah rata-rata sebesar Rp. 67.351,97 per hari, dimana jumlah biaya tidak tetap rata-rata sebesar Rp. 66.572,53 dan biaya tetap sebesar Rp. 779,44 per hari. Dapat disimpulkan bahwa biaya yang berkontribusi besar adalah biaya tidak tetap, hal ini dikarenakan biaya tidak tetap yang dikeluarkan beraneka ragam.

\subsection{Penerimaan}

Penerimaan usaha pengolahan gula kelapa di Desa Sialang Jaya yang tersaji pada Tabel 2. Penerimaan usaha agroindustri adalah perkalian antara jumlah produksi yang diperoleh dengan harga yang berlaku dipasar (Soekartawi, 1998). Tabel 2 menunjukan bahwa penerimaan yang diperoleh yaitu rata- rata sebesar Rp.202.800,00 per produksi. Penerimaan diperoleh dari harga gula kelapa rata- rata Rp. 13.000/kg dikalikan dengan jumlah produksi gula kelapa rata-rata yaitu $390 \mathrm{~kg}$ per produksi. Menurut penelitian Mugiono (2014) rata-rata penerimaan yang didapat dari agroindustri gula merah di Desa Medono Kecamatan Kaliwiro Kabupaten Wonosobo sebesar Rp.468.160,00 per bulan.

Tabel 2. Penerimaan Usaha Pengolahan Gula Kelapa di Desa Sialang Jaya Kecamatan Batang Tuaka Kab. Inhil Per Produksi

\begin{tabular}{cccr}
\hline Produksi & Jumlah Produksi & Harga (Rp) & Jumlah (Rp) \\
\hline Gula Kelapa $(\mathrm{kg})$ & 390 & 13.000 & $202.800,00$ \\
\hline \multicolumn{3}{c}{ Total Penerimaan } & $202.800,00$ \\
\hline
\end{tabular}

Sumber : Data primer diolah, 2018

\subsection{Keuntungan}

Komposisi penerimaan, keuntungan dan efisiensi usaha pengolahan gula kelapa di Desa Sialang Jaya yang tersaji pada Tabel 3. Keuntungan yang diperoleh usaha pengolahan gula kelapa di Desa Sialang Jaya merupakan selisih antara total penerimaan dengan total biaya yang dikeluarkan. Untuk mengetahui besarnya keuntungan pada usaha pengolahan gula kelapa di Desa Sialang Jaya dapat dilihat pada tabel 3 yang menunjukan bahwa keuntungan yang diperoleh sebesar Rp. $135.448,03$ per produksi. Berhasil tidaknya usaha dapat dilihat dari besarnya pendapatan yang diperoleh dalam mengelola suatu 
usaha. Bagi pengusaha analisis ini membantu mereka dalam mengukur apakah kegiatan usaha mereka pada saat ini berhasil atau tidak.

Tabel 3. Komposisi penerimaan, keuntungan dan efisiensi usaha pengolahan gula kelapa di Desa Sialang Jaya Kecamatan Batang Tuaka Per Produksi

\begin{tabular}{lr}
\hline \multicolumn{1}{c}{ Uraian } & \multicolumn{1}{c}{ Jumlah (Rp) } \\
\hline Total Biaya & $67.351,97$ \\
Penerimaan & $202.800,00$ \\
Keuntungan & $135.448,03$ \\
Pendapatan Kerja Dalam Keluarga & $166.227,47$ \\
RCR & 2,94 \\
\hline
\end{tabular}

Sumber : Data primer diolah, 2018

\subsection{Pendapatan Kerja dalam Keluarga}

Pendapatan kerja keluarga merupakan imbalan terhadap bunga harta sendiri, upah tenaga kerja keluarga, dan besarnya penghasilan yang di peroleh. Pada tabel 3 dapat dilihat bahwa jumlah pendapatan kerja dalam keluarga rata- rata sebesar Rp166.227,47 per produksi. Pendapatan kerja keluarga diperoleh dari pendapatan bersih ditambah dengan upah tenaga kerja dalam keluarga dan penyusutan alat. Besarnya pendapatan tenaga kerja dalam keluarga pada usaha pengolahan gula kelapa dikarenakan banyaknya jumlah curahan tenaga kerja dalam keluarga yang digunakan pada usaha ini. Keberhasilan atau kesuksesan usaha dapat dilihat daru sudut ekonomi yaitu besarnya penghasilan atau pendapatan kerja keluarga.

\subsection{Efisiensi}

Efisiensi usaha adalah gambaran layak tidaknya usaha tersebut dilakukan atau diusahakan. Menurut Soekartawi (2002), analisis Return Cost (R/C) ratio merupakan perbandingan (ratio atau nisbah) antara penerimaan (revenue) dan biaya (cost). yang dikeluarkan dalam satu kali produksi. Dari Tabel 3 dapat dilihat bahwa usaha pengolahan santan kelapa di daerah penelitian layak diusahakan, hal ini dapat dilihat dari besarnya $\mathrm{R} / \mathrm{C}$ yang diperoleh yaitu sebesar 2,94 yang berarti bahwa setiap Rp. 1 biaya yang dikeluarkan untuk usaha pengolahan gula kelapa akan menghasilkan pendapatan kotor atau penerimaan sebesar Rp. 2,94 dan pendapatan bersih atau keuntungan sebesar Rp. 1,94. Hal ini senada dengan penelitian yang dilakukan oleh Mugiono (2014), nilai RCR yang diperoleh adalah sebesar 1,3 yang berarti agroindustri gula merah di Desa Medono Kecamatan Kaliwiro Kabupaten Wonosobo menguntungkan dan layak untuk diusahakan.

\section{KESIMPULAN DAN SARAN}

\subsection{Kesimpulan}

1. Rata-rata penerimaan yang diperoleh sebesar Rp. 202.800,00 per produksi, sedangkan rata-rata total biaya yang dikeluarkan adalah sebesar Rp. 67.351,97 per produksi sehingga diperoleh keuntungan rata-rata sebesar Rp. $135.448,03$ per produksi.

2. Nilai efisiensi atau $\mathrm{R} / \mathrm{C}$ yang diperoleh adalah sebesar 2,94 yang berarti bahwa setiap Rp. 1 biaya yang dikeluarkan untuk usaha pengolahan gula kelapa akan menghasilkan pendapatan kotor atau penerimaan sebesar Rp. 2,94 dan pendapatan bersih atau keuntungan sebesar Rp. 1,94. Hal ini menunjukan bahwa usaha pengolahan gula kelapa di 
Desa Sialang Jaya Kecamatan Batang Tuaka efisien atau layak diusahakan.

\subsection{Saran}

1. Pengusaha gula kelapa hendaknya lebih meningkatkan jumlah produksi agar mendapatkan keuntungan maksimal.

2. Pengusaha gula kelapa lebih memperhatikan kualitas gula kelapa untuk menarik konsumen.

\section{DAFTAR PUSTAKA}

Hernanto F. 1989. Ilmu Usahatani.Penebar Swadaya. Jakarta.

Mugiono dkk. 2014. Analisis Pendapatan Usaha Gula Merah Kelapa (Studi Kasus Di Desa Medono Kecamatan Kaliwiro Kabupaten Wonosobo).Skripsi. Universitas Wahid Hasyim. Surakarta.

Ode, W. 2015. Analisis Biaya Dan Pendapatan Pengolahan Gula Aren
Di Desa Tolowe Ponre Waru Kecamatan Wolo Kabupaten Kolaka. Skripsi. Universitas Halu Oleo.

Permatasari Devi. 2014. Analisis Pendapatan Usaha Gula Tumbu di Kecamatan Dawe Kabupaten Kudus. Skripsi. Universitas Diponegoro. Malang.

Santoso,U. 2000. Pengembangan Penelitian Pemanfaatan Kelapa Sebagai Bahan Pangan (Focus Of Research On Coconut As Food). Seminar Nasional Industri Pangan. Fakultas Teknologi Pertanian Universitas Gadjah Mada. Yogyakarta.

Soekartawi. 1998. AnalisisUsahatani. UIPress, Jakarta.

Soekartawi. 2002. Prinsip Dasar Ekonomi Pertanian: Teori Dana Aplikasinya. Raja Grafindo Persada, Jakarta. 